technique and so on. The overall result of this policy is a hybrid of the serological scctions of the usual large microbiological textbook and a techniques manual: and it must be said that on present showing the traditional division is by far the more successful. As regards questions of classification which figure largely here, most people would consider that, important though antigenic structure may be, other criteria like biochemical characteristics or morphology are often no less valuable, but these are not given reasonable emphasis here because of the choice of approach. Nor are the technical details well covered. Complement fixation is a technique that must have been used with virtually every microbial species and so, not surprisingly, it comes up over and over again throughout the text. What the reader will not find is a systematic description of the principles of the mothod. The concept of this book seems to be self-defeating and it can hardly be recommended at any level.

(․ (x. Meynetit

\section{LIPIDS FOR BEGINNERS}

\section{Introduction to Lipids}

By Dennis Chapman. (Europcan Chemistry Sories.) Pp. ix + 141. (Mc(Yraw-Hill: Maidenhead, 1969.) $36 s$.

Professor Chapman has set out to provide an easy first, step for those who wish to understand the chemistry, biochernistry and biophysics of lipids. The objective is admirable because there has been an enormous increase in our knowledge of lipids during the past twenty yoars. The exccution of the book, however, leaves something to be desired.

There is a comprehensive chapter on fatty acids followed by chapters on neutral lipids (glycerides, glyceryl ethers, cholesterol esters and waxes), phosphoglycerides (the longest chapter, 40 pages), sphingolipids and glycosyldiglycerides. A final brief chapter on the role of lipids in biology points out many of the outstanding problems. Most chapter's include information on the chemical synthesis of the molecules being discussed. As would be expected from the author, the treatment of physicochemical aspects of lipids is excollent, though all too brief. Key references, mostly to reviews, are listed after each chapter. There is an appendix on the vexed subject of lipid nomenclature. 'The author makes no attempt to deal with cholesterol, though there is a brief mention of cholesterol esters. This is justified by defining lipids as molecules containing a fatty acid residue. In view of the importance of cholesterol in mammalian metabolism its omission seems unfortunate, as does the lack of information on lipoproteins.

The reader is expected to know what CoA, NAD and CDP are, though he is given the structures of simple carboxylic acids. This scems inconsistent, and the appearance of NAD and DPN on the same page will confuse the beginner. Some information is not very accuratefor instance, the table on page 100 states that $E$. coli has only one phospholipid, phosphatidylethanolamine.

A concise introductory book is extremely difficult to write when it covers such a wide field. In several places the brevity leads to obscurity and error. What will the beginner make of "atherosclerotic losions (xanthomata--. a skin lesion)", for instance? It is also stated that phosphatidic acid acts as an ATPase, that some microsomal RNA is involved in lecithin formation and that plasma membranes are rich in triglyceride. The account of fat absorption omits triglyceride synthesis in the mucosal cell and no montion is made of the monoglyceride pathway. A physical chemist might be exeused for these biochemical errors, but there are also important chemical mistakes. A number of glycolipids are incorrectly drawn (for example, ceramide lactose, ganglioside B3), phos- phatidylinositol is given the D-1 rather than the L-1 structure (page 70), racemic 2-glycerophosphate is reforred to, and galactosyldiglyceride is given an alkyl ether group.

In spite of these minor errors, the book contains a good deal of useful information. 'The printing, particularly of formulae, is very clear.

J. N. HAWTHORNe

\section{PROTEIN INHIBITORS}

Natural Proteinase Inhibitors

By Rosmarie Vogel, Ivar Trautschold and Eugen Werle. Pp. xiv +159 . (Academic Press: New York and London, January 1969.) $93 s 4 d$.

THE dedication of this book is particularly apt because E. K. Frey and H. Kraut together with E. Werle pioneered the first studies on plasma and glandular kallikreins. The subsequent studies of $\mathbf{E}$. Werle clearly demonstrated that the kallikreins hydrolysed by enzymatic action potent biologically active polypoptides, kallidin (bradykinin, nonapeptide) and lysyl-kallidin (decapeptide), from naturally occurring protein substrates (plasma $\alpha_{2}$ globulins).

This book is well presented and is a comprehensive review of protein ixhibitors of the enzymes kallikrein, trypsin, chymotrypsin and plasmin. The kineties of the interaction between enzyme and inhibitor is lucidly discussed. The information on the recently determined structure of $\operatorname{som} \theta$ of the inhibitors and the possible sites and grouping involved in the formation of the exyyme inhibitor complexes is particularly valuable.

Apart from the intrinsic value of the book to those engaged in studies on the cellular control of proteolytic enzymes, the detailed analysis of the interactions between kallikrein, trypsin and plasmin and their naturally occurring protein inhibitors may also be of value to those concerned in clinical research with the treatment of acute pancreatitis, hyperfibrinolysis and shock associated with activation of proteolytic enzymes in anaphylaxis, Gram-negative septicaemia, diabetic acidosis and myocardial infarction.

The authors are to be congratulated on producing this excellent monograph.

K. D. BHHOOLA

\section{LONG-CHAIN MOLECULES}

Statistical Mechanics of Chain Molecules

By Paul J. Flory. Pp. xix +432 . (Interscience (Wiley): New York and London, May 1969.) 164s.

"CompreHension of the configurational statistics of chain molecules is indispensable for a rational inter. pretation and understanding of their properties." ". . . forfeiture of a connection with the actual chemical structure is the inevitable price of adoption of a hypothetical model for interpretation of the properties of the real chain."

These two quotations from the preface summarize the dilemma that polymer physicists and chomists are in at present. A really realistic model, even of a molecule as simple as polymethylene, could not be handled by the most powerful available computers, while the results of "comparison with experiment" of the consequences of simple models are very hard to assess.

This very timely book surveys the growth of a subject that was really started in the $1930 \mathrm{~s}$ by the pioneer work on rubber of Mark, Kuhn and others. On almost every page can be found evidence of the author's vast reading and of the freshness of outlook found only when an active author is contributing to the field himself. Inevitably, his own interests have dictated the selection 